\title{
Hemicellulose and Starch Citrate Chitosan Foam Adsorbents for Removal of Arsenic and Other Heavy Metals from Contaminated Water
}

\begin{abstract}
Abdus Salam, Marielis C. Zambrano, Richard A. Venditti, and Joel J. Pawlak
Arsenic and other heavy metal contaminants in water are a significant global health threat. In this study, low-cost, sulfur-free, sustainable, water-insoluble materials with heavy metal remediation properties were produced from renewable resources such as starch, xylan, citric acid, and chitosan. Synthesized starch citrate-chitosan (SCC) foam and xylan citrate-chitosan (XCC) foam were flexible, porous, and elastic. The foams' arsenic uptake in water was significantly greater than five different commercial metal remediating agents. The mercury and lead uptakes with the synthesized foams were similar to the performance of a commercial sulfur-based product, SorbaTech 450 (ST450). However, the cadmium and selenium uptakes were comparatively lower. The complexation of arsenic with oxygen and nitrogen of the SCC foam was shown with time-of-flight secondary ion mass spectrometry (TOF-SIMS). The XCC foam was also shown to adsorb potassium iodide $(\mathrm{KI})$ at a similar rate to sodium chloride. This may be used to remediate water contaminated with radioactive materials, such as iodine 131.
\end{abstract}

Keywords: Hemicellulose; Xylan; Starch; Citrate; Chitosan; Foam; Arsenic; Heavy metals; Salt; Adsorption

Contact information: North Carolina State University, Department of Forest Biomaterials, Raleigh, NC 27695-8005, USA; *Corresponding author: richardv@ncsu.edu

\section{INTRODUCTION}

The remediation of heavy metal laden waters is a pressing problem. As water quality standards continue to tighten, many industries, such as coal mining, metal manufacturers, electronics, and others, will be required to remove greater portions of dissolved metals from wastewater before discharging. In addition, water contamination with heavy metals, especially arsenic, mercury, and lead, are a significant challenge to a large portion of the world's population. Arsenic is a naturally occurring trace element found in rocks, soils, and the water in contact with them. Arsenic has long been recognized as a toxic element that can contribute to skin, bladder, and other cancers (Asere et al. 2019). There is association between skin cancer and the presence of arsenic in water even at levels below the regulation limits (Mayer and Goldman 2016). There are many locations across the world where the groundwater contains naturally high concentrations of arsenic, as shown in Table 1 (Morton et al. 1976; Matisoff et al. 1982; Welch et al. 1988; Razo et al. 1990; Chatterjee et al. 1995; Nikolaidis et al. 2003; Asere et al. 2019). Besides, contamination of heavy metals is also a relevant issue in mining areas (Zobrist et al. 2009). The United States Environmental Protection Agency (EPA) recently revised the maximum contaminant level (MCL) for arsenic in drinking water from $0.05 \mathrm{mg} / \mathrm{L}$ to $0.01 \mathrm{mg} / \mathrm{L}$, which is the current World Health Organization standard. The MCL of $0.05 \mathrm{mg} / \mathrm{L}$ has been the 
standard since 1942 (Karadede and Ünlü 2000). In the United States, concentrations of lead, mercury, cadmium, and selenium in ground and industrial waters are significantly higher than the EPA standards (Kim et al. 2000).

Table 1. Arsenic and Other Heavy Metals Reported in Water Bodies

\begin{tabular}{|c|c|c|c|}
\hline Heavy Metal & Concentration $(\mu \mathrm{g} / \mathrm{l})$ & Location & Reference \\
\hline Arsenic & 50 to 4,000 & $\begin{array}{l}\text { Ground water in six } \\
\text { districts of west } \\
\text { Bengal, India }\end{array}$ & $\begin{array}{c}\text { (Chatterjee et al. } \\
\text { 1995) }\end{array}$ \\
\hline Arsenic & 8 to 624 & $\begin{array}{c}\text { Aquifers in Region } \\
\text { Lagunera in Northern } \\
\text { Mexico }\end{array}$ & $\begin{array}{c}\text { (Del Razo et al. } \\
\text { 1990) }\end{array}$ \\
\hline Arsenic & 4.7 to 96 & $\begin{array}{l}\text { Canal Futon ground } \\
\text { water in Ohio, USA }\end{array}$ & (Matisoff et al. 1982) \\
\hline Arsenic & 0.1 to 6,000 & $\begin{array}{l}\text { Ground water in } \\
\text { Western United } \\
\text { States }\end{array}$ & (Welch et al. 1988) \\
\hline Arsenic & 0 to 580 & \multirow{3}{*}{$\begin{array}{c}\text { Surface water in } \\
\text { Certej River in a } \\
\text { former mining- } \\
\text { dependent area in the } \\
\text { south of the Apuseni } \\
\text { Mountains, western } \\
\text { Romania } \\
\end{array}$} & \multirow{3}{*}{ (Zobrist et al. 2009) } \\
\hline Cadmium & 0 to 1,400 & & \\
\hline Lead & 0 to 92 & & \\
\hline Cadmium & 0.1 to 4.3 & \multirow{2}{*}{$\begin{array}{l}\text { Baotou section of the } \\
\text { Yellow River, China }\end{array}$} & \multirow{2}{*}{ (Fan et al. 2008) } \\
\hline Lead & 2.5 to 65 & & \\
\hline Lead & 2 to 22 & $\begin{array}{c}\text { Drinking water, } \\
\text { surface water, and } \\
\text { groundwater reported } \\
\text { in USA from } 1996 \text { to } \\
2016\end{array}$ & (Frank et al. 2019) \\
\hline Arsenic & 0 to 3,700 & $\begin{array}{l}\text { Ground water in } \\
\text { several countries } \\
\text { (review paper) }\end{array}$ & (Asere et al. 2019) \\
\hline
\end{tabular}

Another serious problem facing the world is the contamination of drinking water during a nuclear disaster. Iodine 131 is a radioactive isotope that is produced during the radioactive decay of uranium. Iodine 131 can form salts in water and be taken up through the ingestion of water or contaminated foods. During the 2011 Fukashima nuclear crisis in Japan, radiation that was 3,000 times or more of the acceptable limits had been detected in the sea water near the site. While iodine 131 has a half-life of just over 8 days, its potential negative health effects merit the development of strategies to remove it from the drinking water.

Currently available are inorganic or petroleum-based metal chelating agents such as silica, clays, thiol-compounds, carbon disulfide mixed with iron powder, etc. (Lezzi et al. 1994; Matlock et al. 2002). Often these materials carry an active layer of molecules, such as sulfonated compounds, that bind dissolved metals. However, the sulfur in some of these materials may be included in the water phase with its own detrimental effects (Sola et al. 1997). These materials also have low affinity for the counterion and thus are not effective for taking up negatively charged species.

Both ethylenediaminetetraacetic acid (EDTA) and diethylenetriaminepentaacetic acid (DTPA) have an extremely strong complexing capacity with certain dissolved toxic 
heavy metals, resulting in precipitates. The strong complexation occurs because of the affinity of the heavy metal with the lone pair electrons of nitrogen and oxygen atoms in these compounds (Sillanpaa and Oikari 1996). However, it is difficult to separate these small, precipitated particles from the water phase. Many researchers have attempted to develop carbohydrate derivative-based metal chelating agents through chemical modification such as grafting or cross-linking with vinyl monomers (Khalil and AbdelHalim 2001). Ammonium molybdate has also been investigated as an alternative to the existing commercial materials (Dambies et al. 2002). Many of the carbohydrate-based alternatives are toxic or have poor metal complexing performance relative to the existing commercial metal chelating agents (Kim and Lim 1999; Khalil and Abdel-Halim 2000; Khalil and Abdel-Halim 2001; Dambies et al. 2002).

Nevertheless, adsorption could be a low-cost, simple, and eco-friendly alternative, and more natural adsorptive materials should be considered (Asere et al. 2019). Since these materials have poor adsorption capacity, modifications are needed to improve performance (Asere et al. 2019).

Hemicelluloses represent about $20 \%$ to $35 \%$ of the lignocellulosic biomass in trees and plants. Hemicellulose is estimated to account for one-third of all renewable organic carbon available on earth (Ebringerová and Hromádková 1999). Hemicelluloses are a broad class of carbohydrate materials that exhibit some branching with shorter chains than cellulose (Prade 1995). One type of hemicellulose is xylan, which can be found in a wide variety of vascular and woody plants. Certain types of woody plants such as birch (Betula papyrifera) exhibit relatively high amounts of xylan. Often, hemicelluloses are found as organic wastes or byproducts of renewable forest and agricultural products. For instance, in the pulp and papermaking process, significant quantities of hemicellulose are solubilized and burned for energy. It can be estimated that the amount of hemicellulose currently burned in the paper industry worldwide is on the order of 100 million tons per year.

Starch is another renewable polymer that is widely abundant and readily available in a number of commercial forms. The low cost and commercial availability of starch has attracted attempts to develop new functional starch derivatives for industrial applications (Jenkins and Donald 1995; Mauro et al. 2003). The disadvantage of using starch relative to hemicellulose is that starch is also a food product, whereas hemicellulose is not.

However, by themselves, hemicellulose and starch do not have the ability of forming foams and adsorb heavy metals, modifications are needed for this application.

Citric acid is a naturally occurring chemical, generally considered as safe. It is present in nature in citric fruits. It is part of the natural is a common metabolite in plants and animal tissues and an intermediary compound in the Krebs cycle linking oxidative metabolism of carbohydrate, protein, and fat (PubChem n.d.).

Chitosan is a carbohydrate polymer, derived from chitin, and it is a waste material produced in the fishing industry from crab, shrimp, and other shellfish. Chitosan is a $\beta-1,4$ linked polymer of glucose with amino groups primarily located in the 2 position (Poly-(14)-2-amino-2-deoxy- $\beta$-D-glucan). Derivatives of chitosan inhibit the growth of a wide variety of bacteria and fungi (Lim and Hudson 2004; Liu et al. 2004).

The incorporation of carboxylic acids in carbohydrates significantly impart superior hydrophilic properties and improve the water affinity of these materials useful in absorbent applications (Salam et al. 2011a). Starch citrate and hemicellulose citrate were shown to have significantly increased water affinity relative to starch and hemicellulose (Salam et al. 2011a). Besides, the combination of these starch and hemicellulose citrates with chitosan have been determined to have salt complexing and metal scavenging 
properties (Salam et al. 2011a).

In previous research, it was demonstrated that citric acid is an excellent crosslinking agent to produce hemicellulose or starch citrate foams. Starch or hemicellulose alone forms brittle and weak foams and neither starch citrate, hemicellulose citrate or chitosan alone can form foams after freeze drying (Salam et al. 2010, 2011a). It was found that hemicellulose-citrate or starch-citrate combined with chitosan under the proper reaction conditions developed hydrogel foams (Salam et al. 2011a).

The crosslinked citrate- starch-chitosan and citrate- hemicellulose-chitosan foams are flexible and elastic and have significantly increased absorbance and strength and decreased weight loss in water compared to starch-chitosan or hemicellulose-chitosan foams, respectively. It is considered that the crosslinking between the starch and hemicellulose with chitosan is responsible for the elastic nature the foam. A unique characteristic of these foams crosslinked with citric acid is that they absorb more saline solution than pure water, which is the opposite of current commercial superabsorbents (Salam et al. 2010, 2011b).

In the current investigation, the goal was to assess the application of these materials as adsorbents in the remediation of water contaminated with heavy metals. The metal uptake of these materials for arsenic, lead, mercury, cadmium, and selenium was studied. The interesting and novel aspect of this material is that it is broadly effective on several different dissolved species both with both positive and negative charges. Also, this material is made from waste products that originate from natural sources. The uptake of salts, such as sodium chloride and potassium iodide (KI), were examined as well.

\section{EXPERIMENTAL}

\section{Methods and Materials \\ Materials}

Corn starch was supplied by Cargill Inc. (Minneapolis, USA) (lot number C3J121B). This starch is a mixture of amylose ( $\alpha-1,4$ glucose) and amylopectin (branched polymer of amylose). The hemicellulose utilized was xylan (poly $(\beta-D$-xylopyranse[1-4]) from birchwood with xylose residues of greater than $90 \%$ by high-performance anion exchange (product number X0502; Sigma-Aldrich, St. Louis, USA). The chitosan viscosity-based molecular weight $\left(M_{\mathrm{v}}\right.$ 141,836), degree of deacetylation 83\% (Fouriertransform infrared and titration)) CAS registry number 9012-76-4 was purchased from Sigma-Aldrich (St. Louis, USA). The reagent grade chemicals utilized were sodium hypophosphate (CAS registry number 123333-67-5) and citric acid (CAS registry number 77-92-9), both of which were purchased from Fisher Scientific (Fair Lawn, USA). Arsenic (CAS registry number 10003-1) was obtained from High-Purity Standards (Charlotte, USA). The arsenic standard is traceable to NIST SRM 3303 and is composed of Arsenic at $1000 \mu \mathrm{g} / \mathrm{ml}$ dissolved in $2 \%$ nitric acid $\left(\mathrm{As}+5 \mathrm{HNO}_{3} \rightarrow \mathrm{H}_{3} \mathrm{AsO}_{4}+5 \mathrm{NO}_{2}+\mathrm{H}_{2} \mathrm{O}\right)$. Selenium (CAS registry number 7782-49-2) was obtained from Acros Organics (Fair Lawn, USA). This selenium was dissolved in $2 \%$ nitric acid $\left(\mathrm{Se}+4 \mathrm{HNO}_{3} \rightarrow \mathrm{H}_{2} \mathrm{SeO}_{3}+\right.$ $4 \mathrm{NO}_{2}+\mathrm{H}_{2} \mathrm{O}$ ). Lead (CAS registry number 13-641-773) was obtained from Orion Research Inc. (Cambridge, USA). The standard lead solution was prepared with Lead Perchlorate, Hexahydrate $\left(\mathrm{Pb}\left(\mathrm{ClO}_{4}\right)_{2} * 6 \mathrm{H}_{2} \mathrm{O}\right)$ in deionized water creating a $\mathrm{Pb}^{+2}$ valence. Mercury (part number SPEC-HG2, SPEX CertiPre, Metuchen USA) was prepared in a $10 \%$ nitric acid $\left(\mathrm{Hg}+4 \mathrm{HNO}_{3} \rightarrow \mathrm{Hg}\left(\mathrm{NO}_{3}\right)_{2}+2 \mathrm{NO}_{2}+2 \mathrm{H}_{2} \mathrm{O}\right)$. Cadmium in $2 \%$ nitric acid $\left(\mathrm{Cd}+4 \mathrm{HNO}_{3} \rightarrow\right.$ 
$\left.\mathrm{Cd}\left(\mathrm{NO}_{3}\right)_{2}+2 \mathrm{NO}_{2}+2 \mathrm{H}_{2} \mathrm{O}\right)$, part number SPEC-CD2, was obtained from SPEX CertiPrep (Metuchen USA). Commercial metal uptake materials were obtained from several sources. The commercial metal chelating agent, LayneRT hybrid ion exchange resin (quaternary amine styrene divinylbenzene copolymer in the sulfate/iron oxide form), was obtained from Solmetex (Northborough, USA). Absorbia GTO (a granular titanium dioxide resin) was obtained from Dow Chemical (Midland, USA). Alumina (a mixture of aluminum oxide, ferric oxide, ferric hydroxide, sodium oxide, and sodium sulfate) was obtained from Rio Tinto Alcan (Montreal, Canada). SorbaTech 450 (ST450) (a mixture of silicate, mesostructured, and organo-silane) was obtained from Energy \& Environmental Enterprises, LLC (Atlanta, USA). PuroliteFerrIX ${ }^{\mathrm{TM}}$ A33E ion exchange resin (a mixture of benzene, diethenyl- polymer with ethenylbenzene, sulfonated, and iron salts) was obtained from the Purolite Company (Bala Cynwyd, USA).

\section{Synthesis of Starch/Xylan Derivatives}

Five grams of citric acid was dissolved in $6 \mathrm{~mL}$ of water in a glass beaker. Five grams of xylan or starch was combined with the citric acid solution in a $100 \mathrm{~mL}$ glass beaker and vigorously mixed with a glass rod by hand (Fig. 1, I and II). The mixture was placed in a forced air oven to dehydrate at $100{ }^{\circ} \mathrm{C}$ for $30 \mathrm{~min}$. At this point, all of the surface moisture was removed, and the starch or hemicellulose particles were coated with citric acid. The mixtures were allowed to react in the oven at pre-determined conditions. The xylan was conditioned for $5 \mathrm{~h}$ at $115^{\circ} \mathrm{C}$, and the starch was conditioned for $6 \mathrm{~h}$ at $120^{\circ} \mathrm{C}$. The times and temperatures for the reaction were determined from several trial experiments in which times and temperatures were varied. The reaction products were mixed in $60 \mathrm{~mL}$ of water for $30 \mathrm{~min}$, adjusted to $\mathrm{pH} 2$ using acetic acid, filtered on Whatman 4 Qualitative filter paper Grade CFP4, and washed with $100 \mathrm{~mL}$ of water. The product was air-dried overnight and the filtrate was evaporated to obtain a weight for yield determination (Salam 2011a). This reaction method was simple and did not involve organic solvents, making it a relatively green and environmentally friendly reaction scheme. The ratio of citric acid to xylan was determined from previous work, which showed good efficiency for the reaction at this ratio (Prade 1995).

\section{Cross Linking Reaction}

A chitosan solution was prepared by adding $1 \mathrm{~g}$ of chitosan to a mixture of $99 \mathrm{~g}$ of water and $1 \mathrm{~mL}$ of glacial acetic acid. The chitosan solution was added to $100 \mathrm{~g}$ of $1 \%$ xylan citrate or starch citrate solution in a $500 \mathrm{~mL}$ round bottom flask (Fig. 1, III). The $\mathrm{pH}$ was then adjusted to 3.5 with sodium acetate. The reaction mixture was stirred using a magnetic stirrer at $100{ }^{\circ} \mathrm{C}$ for $3 \mathrm{~h}$, followed by ambient cooling to room temperature for approximately $1 \mathrm{~h}$. Then, the xylan citrate-chitosan (XCC) or starch citrate-chitosan (SCC) product was freeze dried (Salam et al. 2011b). Figure 1 shows a proposed scheme for the creation of a carbohydrate cross linked with chitosan via citric acid. Figure 2 shows images of the carbohydrate-based foams and scanning electron microscope (SEM) images of the detailed structure of the foam.

\section{Characterization of Metal Uptake}

Completely mixed batch reactors were used to determine the metal uptake. Deionized water was used to make up the test solutions. Arsenic $\left(\mathrm{H}_{3} \mathrm{AsO}_{4}\right)$, mercury $\left(\mathrm{Hg}\left(\mathrm{NO}_{3}\right)_{2}\right)$, cadmium $\left(\mathrm{Cd}\left(\mathrm{NO}_{3}\right)_{2}\right)$, lead $\left(\mathrm{Pb}\left(\mathrm{ClO}_{4}\right)_{2} * 6 \mathrm{H}_{2} \mathrm{O}\right)$, and selenium $\left(\mathrm{H}_{2} \mathrm{SeO}_{3}\right)$ solutions were evaluated individually. 
Esterification of carbohydrates with citric acid:

I) Formation of critic acid anhydride:

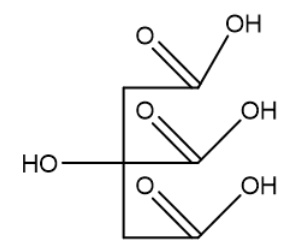

Critic Acid

I) Esterification of carbohydrates:

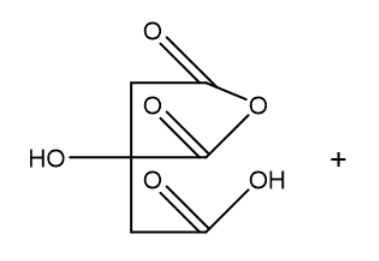

Critic Acid Anhydride

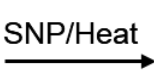

$\mathrm{Z}-\mathrm{OH}$

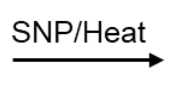

Z: Starch or
Xylan

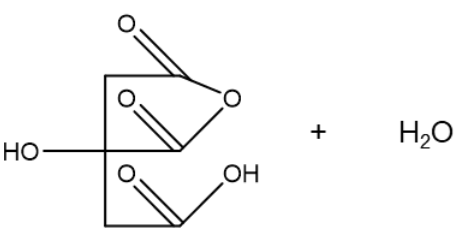

Critic Acid Anhydride
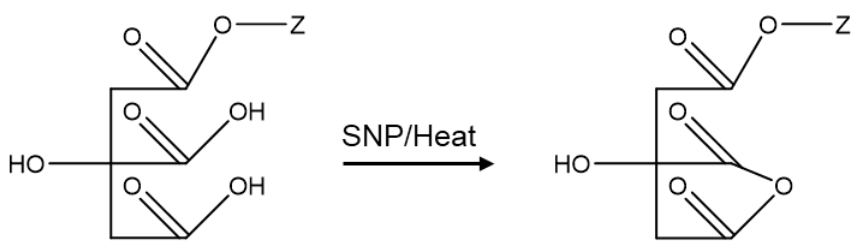

III) Crosslinking of $Z$ citrate with Chitosan:
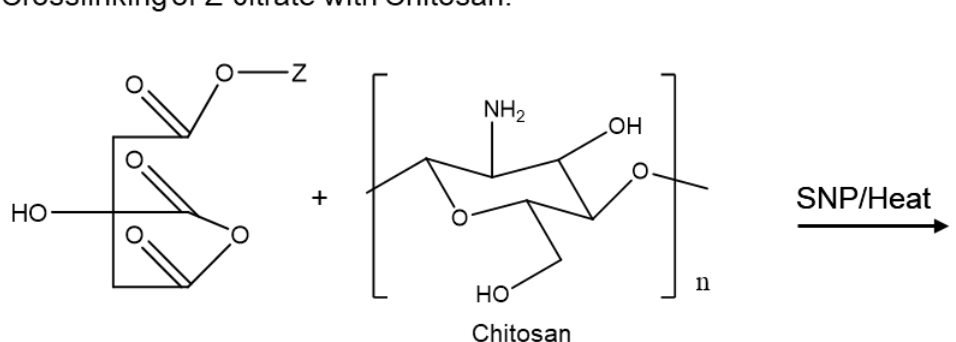

$\mathrm{H}_{2} \mathrm{O}$

Chitosan

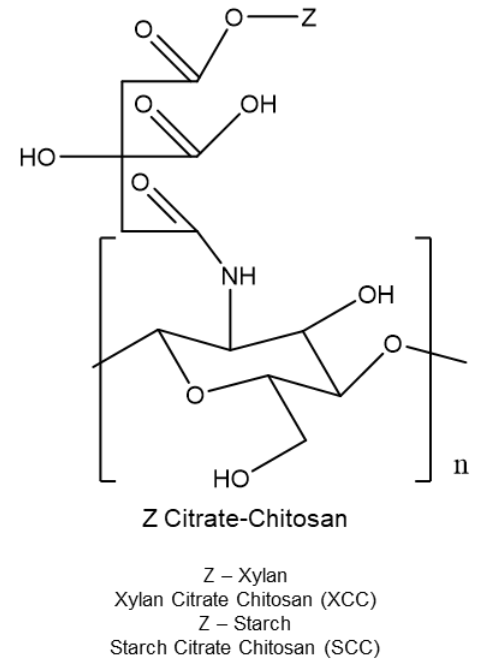

Fig. 1. Proposed schematic of the esterification of hemicellulose or starch (i.e. carbohydrate) with citric acid and chitosan. The crosslinking reaction does not require that the citric acid first crosslinks the hemicellulose. It is possible for a similar reaction to occur if the citric acid is only bonded to a single carbohydrate molecule (Salam et al. 2010, 2011b).

Polyethylene vials were prepared with approximately $0.025 \mathrm{~g}$ of SCC or XCC foam and $50 \mathrm{~mL}$ of standard metal solution. The $\mathrm{pH}$ of the metal solutions was 5.1. The flasks were agitated by hand for $6 \mathrm{~m}$ and then filtered through the Whatman 4 Qualitative filter paper Grade CFP4 with a house vacuum. Two drops of $2 \%$ nitric acid were added to the approximately $50 \mathrm{~mL}$ of filtrate to get a $\mathrm{pH}$ of 2 . The concentrations of the filtrate were 
measured by an Inductively-Coupled Plasma Optical Emission Spectrometer (ICP-OES) (2000 DV; PerkinElmer, Shelton, USA). Duplicate experiments on the absorption of lead $(\mathrm{Pb})$ in a $50 \mathrm{mg} / \mathrm{L}$ solution indicated a $1.4 \%$ difference in the adsorbed amounts detected for a blank experiment, a 3.9\% difference for an XCC experiment, a $6.1 \%$ difference for a SCC experiment, and a $13.1 \%$ difference for a ST450 experiment.
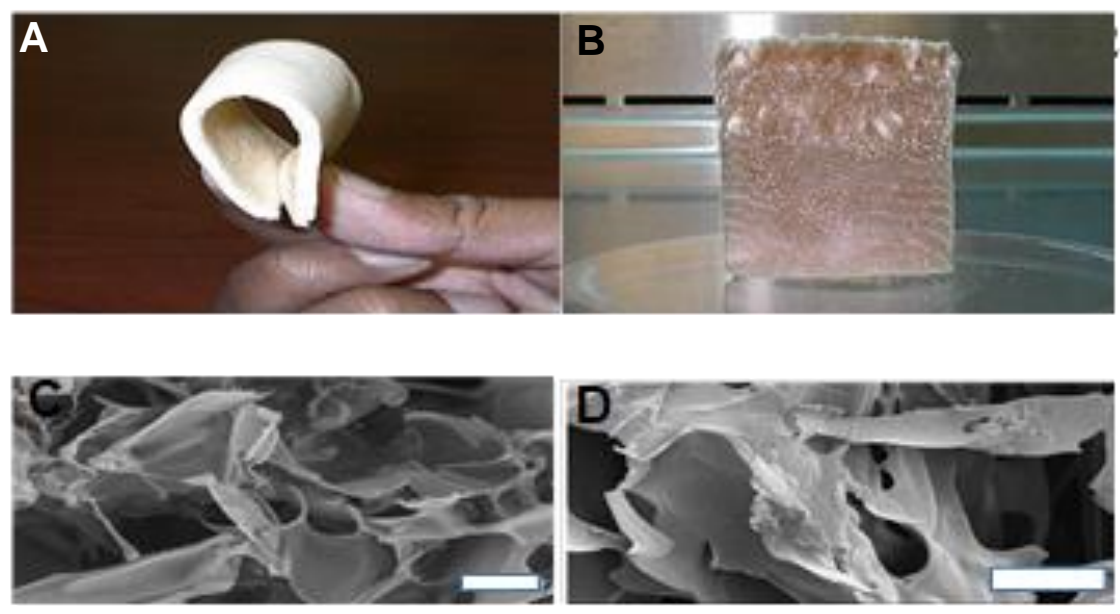

Fig. 2. (A) XCC foam showing elasticity during a deformation, (B) SCC foam of approximately $4 \mathrm{~cm}$ wide (C) SEM image of XCC foam (left), and (D) SEM image of SCC foam. The white bars in 2C and $2 \mathrm{D}$ indicate a length of 50 -micron length scale.

\section{Eqilibrium Adsorption Isotherms}

The equilibrium adsorption isotherms were determined using samples that had a fixed amount of adsorbent, but with varying initial concentrations of heavy metals. The equilibrium adsorption results were analyzed with the Langmuir model (Langmuir 1918; Haider and Park 2009), as seen in Eqs. 1 and 2 (linear form),

$$
\begin{aligned}
& q_{e}=\frac{q_{m} K_{a} C_{e}}{1+K_{a} C_{e}} \\
& \frac{1}{q_{e}}=\frac{1}{q_{m}}+\frac{1}{q_{m} K_{a} C_{e}}
\end{aligned}
$$

where $q_{\mathrm{e}}$ is the equilibrium quantity of the metal ions adsorbed onto the substrate foam $(\mathrm{mg} / \mathrm{g}), C_{\mathrm{e}}$ is the equilibrium concentration of the adsorbate $(\mathrm{mg} / \mathrm{L}), q_{\mathrm{m}}$ is the maximum adsorption capacity $(\mathrm{mg} / \mathrm{g})$, and $K_{\mathrm{a}}$ is the Langmuir equilibrium constant $(\mathrm{L} / \mathrm{mg})$. The data were analyzed using this model for absorption. Outliers were eliminated from the analysis, and at least four data points were in all cases reported. In some cases, the data did not follow the Langmuir model and the resulting maximum absorption capacity was not reported.

\section{Metal Complexation Characterization with Time-of-Flight Secondary Ion Mass Spectrometry (TOF-SIMS)}

Time-of-flight secondary ion mass spectrometry was used to identify the complexes formed between a heavy metal and the SCC foam by analyzing the unexposed foam and $\mathrm{SCC}$ foam exposed to a $50 \mathrm{mg} / \mathrm{L}$ solution of arsenic. The TOF-SIMS data was acquired using a TOF-SIMS V (IONTOF, Chestnut Ridge, USA) under both high mass and high spatial resolution conditions. For the acquisition conditions, images of a $100 \mu \mathrm{m}$ area were acquired with a $128 \times 128$ and $256 \times 256$ pixel resolution using a $\mathrm{Bi}_{3}{ }^{+}$primary ion beam. For all acquisitions, a complete mass spectrum was acquired and stored for each pixel. Data 
acquisition was continued until a sufficient signal to noise ratio was achieved. The mass spectra (the summation of all the spectra acquired for a particular sample) and images were generated from either single peaks or from groups of peaks of interest (Belu et al. 2003; Yuko et al. 2011).

\section{Evaluation of Salt Uptake}

The uptake of dissolved salts was determined by four measurements. First, various concentration of salt solutions (KI) were prepared using reagent grade chemicals and deionized water. A volume of $25 \mathrm{~mL}$ of the salt solution was added to a beaker. Then, 0.025 $\mathrm{g}$ of the adsorbent material (XCC or SCC) was added to the beaker and allowed to interact with the solution for $20 \mathrm{~min}$. The conductivity of the solution was measured before and after the material was placed into the solution. The concentration of the salt in the solution was determined from a calibration curve and the salt uptake was measured. The material was then removed from the solution and dried. The dry weight of the sample increased, which can be used as an indication of salt uptake. These measurements include salt that was bound or concentrated by the material as well as the solution that was taken up by the material. Furthermore, the solution can also be evaporated to determine the amount of salt remaining in the solution. Finally, the sample was thermally degraded via thermogravimetric analysis (TGA) to determine the amount of char remaining at $600{ }^{\circ} \mathrm{C}$. The use of TGA can also determine the salt uptake when compared to a "blank" sample. Each of these methods was used to verify the uptake of salt by the adsorbent material.

\section{RESULTS AND DISCUSSION}

\section{Arsenic and Heavy Metal Absorption}

Arsenic

Individual batch experiments were conducted with SCC, XCC, and other substrates for several concentrations of arsenic, as can be seen in Table 2.

Table 2. Effect of Arsenic Loading onto XCC, SCC, and STP450 (Adsorbent 0.025 $\mathrm{g}, 50 \mathrm{~mL}$ Solution, and $6 \mathrm{~min}$ )

\begin{tabular}{|c|c|c|c|}
\hline Sample & $\begin{array}{c}\text { Initial Concentration } \\
(\mu \mathrm{g} / \mathrm{L})\end{array}$ & $\begin{array}{c}\text { Final Concentration } \\
(\mu \mathrm{g} / \mathrm{L})\end{array}$ & $\begin{array}{c}\text { Metal Loading } \\
(\mathrm{mg} / \mathrm{g})\end{array}$ \\
\hline XCC & 50,100 & 45,000 & 10.12 \\
& 26,200 & 21,800 & 8.75 \\
& 12,700 & 11,000 & 3.37 \\
& 4,950 & 4,310 & 1.27 \\
& 100.8 & 91.5 & 0.02 \\
\hline SCC & 50,100 & 45,400 & 9.32 \\
& 26,200 & 22,200 & 7.95 \\
& 12,700 & 10,600 & 4.17 \\
& 4,950 & 4,030 & 1.83 \\
& 100.8 & 47.6 & 0.10 \\
\hline \multirow{3}{*}{ ST450 } & 50,100 & 45,600 & 8.92 \\
& 26,200 & 24,300 & 3.75 \\
& 12,700 & 11,900 & 1.57 \\
& 4,950 & 4,900 & 0.09 \\
& 100.8 & 92.2 & 0.02 \\
\hline
\end{tabular}


To recover the solids after the batch experiments, the material was filtered using Whatman 4 Qualitative filter paper Grade CFP4. It was determined in separate experiments that the filter paper adsorbed approximately $0.017 \mathrm{mg} / \mathrm{g}$ arsenic present or $0.02 \mathrm{mg} / \mathrm{g}$ of filter paper. This was not a significant amount relative to the reproducibility of the tests. The results in this study have been corrected for this. The arsenic loading increased for both SCC and XCC as the arsenic concentration increased. A similar trend was observed for the ST450. The arsenic uptake was higher at all arsenic concentrations for both SCC and XCC relative to the ST450.

The arsenic uptake at a mid-concentration of 4,950 parts per billion (ppb) was investigated for the XCC, the SCC, the commercial metal adsorbers, and several commercial/control materials (Table 3).

Table 3. Arsenic Uptake for Various Materials in a 4,950 $\mu \mathrm{g} / \mathrm{L}$ Solution (Adsorbent $0.025 \mathrm{~g}, 50 \mathrm{~mL}$, solution and $6 \mathrm{~min}$ )

\begin{tabular}{|c|c|c|c|}
\hline Sample & $\begin{array}{c}\text { Initial } \\
\text { Concentration } \\
(\mu \mathrm{g} / \mathrm{L})\end{array}$ & $\begin{array}{c}\text { Final } \\
\text { Concentration } \\
(\mu \mathrm{g} / \mathrm{L})\end{array}$ & $\begin{array}{c}\text { Metal Loading } \\
(\mathrm{mg} / \mathrm{g})\end{array}$ \\
\hline XCC & 4,950 & 4,310 & 1.26 \\
\hline SCC & 4,950 & 4,030 & 1.82 \\
\hline Starch Citrate & 4,950 & 4,510 & 1.14 \\
\hline Starch & 4,950 & 4,734 & 0.41 \\
\hline Chitosan & 4,950 & 4,366 & 0.86 \\
\hline Pulp Fibers (Hardwood) & 4,950 & 4,778 & 0.02 \\
\hline Filter Paper & 4,950 & 4,610 & 0.02 \\
\hline ST450 & 4,950 & 4,900 & 0.08 \\
\hline LayneRT & 4,950 & 4,750 & 0.38 \\
\hline Alumina & 4,950 & 4,710 & 0.46 \\
\hline PuroliteFerrIX A33E & 4,950 & 4,680 & 0.52 \\
\hline Absorbia GTO & 4,950 & 4,930 & 0.03 \\
\hline
\end{tabular}

Even the control samples of starch, chitosan, and starch citrate were able to adsorb some metals. In particular, chitosan had an appreciably higher metal loading. This is in agreement with the literature results, which indicate that chitosan/chitin was able to uptake arsenic at $0.13 \mu \mathrm{mol} / \mathrm{g}$ at the concentration $0.3 \mathrm{ppm}$ (Elson et al. 1980). Relative to several commercial materials, the XCC and SCC have very favorable metal uptakes at the 4,950 ppb level. The combination of these materials in the XCC and SCC foams appeared to improve the uptake relative to these materials.

\section{Lead}

The results for lead loading of XCC, SCC, and ST450 are shown in Table 4. The lead absorption increased with the increased lead concentration up to 40,000 ppb. Above $40,000 \mathrm{ppb}$, the lead absorption remained essentially flat, increasing slightly for the XCC but decreasing slightly for the other materials. This may be an indication that the material is essentially saturated at this concentration of lead and this amount of adsorbent. For all three materials, the lead absorption was very comparable. This is notable in that the ST450 is a sulfur-based absorption medium that is known for its lead uptake, while XCC and SCC do not contain sulfur. The typical concentration for polluted water is at or below $100 \mathrm{ppb}$ for lead. The lead loading at $83 \mathrm{ppb}$ was $0.10 \mathrm{mg} / \mathrm{g}, 0.11 \mathrm{mg} / \mathrm{g}$, and $0.11 \mathrm{mg} / \mathrm{g}$ for XCC, SCC, and ST450, respectively. Thus, the low cost and sulfur free XCC and SCC may 
provide an economic and environmental advantage when compared to commercial adsorbents.

Table 4. Effect of Lead Loading onto XCC, SCC, and STP450 (Adsorbent 0.025 $\mathrm{g}, 50 \mathrm{~mL}$ solution, and $6 \mathrm{~min}$ )

\begin{tabular}{|c|c|c|c|}
\hline Sample & $\begin{array}{c}\text { Initial Concentration } \\
(\mu \mathrm{g} / \mathrm{L})\end{array}$ & $\begin{array}{c}\text { Final Concentration } \\
(\mu \mathrm{g} / \mathrm{L})\end{array}$ & $\begin{array}{c}\text { Metal Loading } \\
(\mathrm{mg} / \mathrm{g})\end{array}$ \\
\hline XCC & 70,900 & 55,900 & 29.86 \\
& 40,400 & 27,400 & 25.94 \\
& 24,900 & 14,600 & 20.54 \\
& 6,850 & 5,580 & 2.52 \\
& 83.0 & 35.8 & 0.1 \\
\hline SCC & 70,900 & 54,400 & 32.86 \\
& 40,400 & 24,500 & 31.74 \\
& 24,900 & 14,300 & 21.14 \\
& 6,850 & 5,400 & 2.88 \\
& 83.0 & 30.3 & 0.11 \\
\hline \multirow{3}{*}{ ST450 } & 70,900 & 52,450 & 36.76 \\
& 40,400 & 23,800 & 33.14 \\
& 24,900 & 11,700 & 26.34 \\
& 6,850 & 4,420 & 4.84 \\
& 83.0 & 28.7 & 0.11 \\
\hline
\end{tabular}

\section{Mercury}

Table 5 shows the mercury uptake over a range of concentrations from $95 \mathrm{ppb}$ to $38,400 \mathrm{ppb}$. The mercury absorption increased with increased mercury concentration. The mercury absorption of XCC foam was slightly lower than that of ST450 at 38,400 ppb. However, at the mid to lower concentration (2,000 ppb to $95 \mathrm{ppb})$, the mercury absorption of XCC foam was better than that of commercial ST450. At the lowest concentration of 95 $\mathrm{ppb}$, the mercury loading of XCC, SCC, and ST450 was $0.19 \mathrm{mg} / \mathrm{g}, 0.15 \mathrm{mg} / \mathrm{g}$, and 0.18 $\mathrm{mg} / \mathrm{g}$, respectively.

Table 5. Effect of Mercury Loading onto XCC, SCC, and STP450 (Adsorbent $0.025 \mathrm{~g}, 50 \mathrm{~mL}$ solution, and $6 \mathrm{~min}$ )

\begin{tabular}{|c|c|c|c|}
\hline Sample & $\begin{array}{c}\text { Initial Concentration } \\
(\mu \mathrm{g} / \mathrm{L})\end{array}$ & $\begin{array}{c}\text { Final Concentration } \\
(\mu \mathrm{g} / \mathrm{L})\end{array}$ & $\begin{array}{c}\text { Metal Loading } \\
(\mathrm{mg} / \mathrm{g})\end{array}$ \\
\hline XCC & 38,400 & 7,900 & 60.84 \\
& 28,300 & 5,750 & 44.95 \\
& 12,200 & 266 & 23.8 \\
& 3,650 & 000 & 7.28 \\
& 95.1 & 2.24 & 0.19 \\
\hline SCC & 38,400 & 15,200 & 46.24 \\
& 28,300 & 7,860 & 40.75 \\
& 12,200 & 106 & 24.10 \\
& 3,650 & 132 & 7.02 \\
& 95.1 & 22.1 & 0.15 \\
\hline \multirow{3}{*}{ ST450 } & 38,400 & 4,300 & 68.04 \\
& 2,8300 & 4,320 & 47.75 \\
& 1,2200 & 956 & 22.8 \\
& 3,650 & 125 & 7.03 \\
& 95.1 & 4.43 & 0.18 \\
\hline
\end{tabular}




\section{Cadmium}

Table 6 shows that the cadmium absorption increased with the increased cadmium concentration. The cadmium absorption of XCC or SCC was lower than ST450 at all the concentration levels except for $26,700 \mathrm{ppb}$. The cadmium loading by XCC, SCC, and ST450 was $0.08 \mathrm{mg} / \mathrm{g}, 0.03 \mathrm{mg} / \mathrm{g}$, and $0.14 \mathrm{mg} / \mathrm{g}$, respectively, at the concentration of 78 ppb of cadmium.

Table 6. Effect of Cadmium Loading onto XCC, SCC, and STP450 (Adsorbent $0.025 \mathrm{~g}, 50 \mathrm{~mL}$ solution, and $6 \mathrm{~min}$ )

\begin{tabular}{|c|c|c|c|}
\hline Sample & $\begin{array}{c}\text { Initial Concentration } \\
(\mu \mathrm{g} / \mathrm{L})\end{array}$ & $\begin{array}{c}\text { Final Concentration } \\
(\mu \mathrm{g} / \mathrm{L})\end{array}$ & $\begin{array}{c}\text { Metal Loading } \\
(\mathrm{mg} / \mathrm{g})\end{array}$ \\
\hline XCC & 53,200 & 49,000 & 8.32 \\
& 26,700 & 24,500 & 4.34 \\
& 12,700 & 12,000 & 1.37 \\
& 5,290 & 4970 & 0.43 \\
& 78.0 & 40.0 & 0.08 \\
\hline SCC & 53,200 & 50,500 & 5.32 \\
& 26,700 & 23,900 & 5.54 \\
& 12,700 & 11,600 & 2.17 \\
& 5,290 & 4,940 & 0.68 \\
& 78.0 & 64.9 & 0.03 \\
\hline \multirow{3}{*}{ ST450 } & & 47,400 & 11.52 \\
& 53,200 & 24,500 & 4.34 \\
& 26,700 & 11,700 & 1.97 \\
& 12,700 & 4,540 & 1.48 \\
& 5,290 & 8.8 & 0.14 \\
\hline
\end{tabular}

\section{Selenium}

As the selenium concentration increased, the selenium adsorption increased with XCC, SCC, and ST450 (Table 7). The selenium adsorption with XCC and SCC was almost half that of the commercial ST450 for all concentrations evaluated.

Table 7. Effect of Selenium Loading onto XCC, SCC, and STP450 (Adsorbent $0.025 \mathrm{~g}, 50 \mathrm{~mL}$ solution, and $6 \mathrm{~min}$ )

\begin{tabular}{|c|c|c|c|}
\hline Sample & $\begin{array}{c}\text { Initial Concentration } \\
(\mu \mathrm{g} / \mathrm{L})\end{array}$ & $\begin{array}{c}\text { Final Concentration } \\
(\mu \mathrm{g} / \mathrm{L})\end{array}$ & $\begin{array}{c}\text { Metal Loading } \\
(\mathrm{mg} / \mathrm{g})\end{array}$ \\
\hline XCC & 53,400 & 48,400 & 9.95 \\
& 26,900 & 24,200 & 5.35 \\
& 14,500 & 12,500 & 3.98 \\
& 5,630 & 4,520 & 2.21 \\
& 110 & 100 & 0.01 \\
\hline SCC & 53,400 & 48,700 & 9.34 \\
& 26,900 & 24,700 & 4.35 \\
& 14,500 & 12,400 & 4.18 \\
& 5,630 & 4,880 & 1.49 \\
& 110 & 97.6 & 0.03 \\
\hline \multirow{3}{*}{ ST450 } & 53,400 & 42,300 & 14.74 \\
& 26,900 & 21,700 & 10.35 \\
& 14,500 & 9,860 & 9.18 \\
& 5,630 & 2,620 & 6.01 \\
& 110 & 18.4 & 0.18 \\
\hline
\end{tabular}


The high metal ion uptake of XCC and SCC is attributed to the composition of these materials, as they contain amino and carboxylic groups. These functional groups are similar to those found in EDTA and DTPA and are responsible for the metal chelating capabilities in these materials for positive ions (Sillanpaa and Oikari 1996). In contrast to EDTA and DTPA, XCC and SCC contain and a $-\mathrm{NH}$ group that is protonated $\left(-\mathrm{NH}^{+}\right)$at $\mathrm{pH} 5.1$ and it is able to interact with the negative ions from arsenic and selenium (Kwok et al. 2014; Shchipunov et al. 2010). The advantage of XCC or SCC over EDTA and DTPA are that $\mathrm{XCC}$ and SCC are not soluble, and as swollen gels they can be easily separated from the aqueous solution.

\section{Isothermal Adsorption}

The data presented in Tables 2 through 7 show that XCC, SCC, and ST450 can all adsorb an appreciable amount of heavy metals at higher concentrations. However, the results also indicate that the effectiveness of the uptake decreases as the concentration decreases. In water remediation situations, the adsorbent must be able to remove contaminants when they are at very low concentrations. One way to characterize the absolute efficiency of an adsorbent is through its isothermal adsorption constant. The maximum amount of heavy metal uptake, $q_{\mathrm{m}}$ (Eq. 1), can be evaluated by fitting the data to a linearized Langmuir isotherm.

Not all of the combinations of materials and heavy metals were well represented by a Langmuir isotherm. The XCC, SCC, and ST450 were able to be characterized using a Langmuir isothermal adsorption model. The data indicated that for lead, the XCC $\left(q_{\mathrm{m}}=\right.$ $\left.36.6 \mathrm{mg} / \mathrm{g}, \mathrm{R}^{2}=0.99\right)$ and $\mathrm{SCC}\left(q_{\mathrm{m}}=39.7 \mathrm{mg} / \mathrm{g}, \mathrm{R}^{2}=0.99\right)$ were comparable to the sulfur based ST450 $\left(q_{\mathrm{m}}=44.1 \mathrm{mg} / \mathrm{g}, \mathrm{R}^{2}=0.99\right)$. A similar result was found for selenium, where the XCC, SCC, and ST450 had uptake values of $16.4 \mathrm{mg} / \mathrm{g}\left(\mathrm{R}^{2}=0.8\right), 19.6 \mathrm{mg} / \mathrm{g}\left(\mathrm{R}^{2}=\right.$ $0.61)$, and $15.3 \mathrm{mg} / \mathrm{g}\left(\mathrm{R}^{2}=0.99\right)$, respectively. The performance of ST450 in relationship to mercury was better $\left(q_{\mathrm{m}}=79.4 \mathrm{mg} / \mathrm{g}, \mathrm{R}^{2}=0.87\right)$, but the XCC $\left(q_{\mathrm{m}}=57.8 \mathrm{mg} / \mathrm{g}, \mathrm{R}^{2}=\right.$ $0.96)$ and $\operatorname{SCC}\left(q_{\mathrm{m}}=55.9 \mathrm{mg} / \mathrm{g}, \mathrm{R}^{2}=0.82\right)$ also showed a significant ability to bind the heavy metals. The binding of metals is a relatively complex phenomenon that involves the active adsorption site structure as well as atomic structure of the adsorbed metals. In general, it is difficult to predict the relative efficiency of different adsorbers.

These results also indicate that some adsorbers may not be well represented by Langmuir isotherms. For example, the adsorption data for cadmium was not well represented by the Langmuir isotherm for any of the three materials. In the case of arsenic, only the SCC showed a notable $q_{\mathrm{m}}\left(12.4 \mathrm{mg} / \mathrm{g}, \mathrm{R}^{2}=0.87\right)$. However, to better understand the adsorption of arsenic, the interaction between SCC and arsenic was further investigated.

\section{Arsenic Complexation Analysis}

Figures 3 and 4 show the high spatial resolution (and thus low mass resolution) TOF-SIMS images of $\mathrm{CN}^{-}, \mathrm{CNO}^{-}, \mathrm{AsO}_{2}^{-}$, and $\mathrm{AsCNO}^{-}$for the control and arsenic adsorbed samples.

While these images clearly demonstrate the spatial resolution of the $\mathrm{Bi}_{3}{ }^{+}$primary ion beam under these conditions, it is not possible to separate mass interference from the arsenic-containing peaks of interest and thus it is not possible to obtain the arsenic spatial distribution from these images. 
Comparison of the high mass resolution spectra of $\mathrm{As}, \mathrm{AsO}, \mathrm{AsO}_{2}$, and $\mathrm{AsCNO}$ obtained from the arsenic exposed samples to those obtained under identical experimental conditions from the control sample clearly show the presence of arsenic on the surface of the exposed samples. However, the images obtained under high mass resolution conditions (having approximately $10 \mu \mathrm{m}$ spatial resolution) show a non-uniform arsenic distribution. It is also observed from the high mass resolution spectra (Fig. 4) that the arsenic is complexing with oxygen and nitrogen of the SCC. This may be explained by the oxygen of the hydroxyl groups and the nitrogen of the amino groups of the SCC materials having unpaired electrons, which may interact with arsenic. This is in agreement with other studies (Sillanpaa and Oikari 1996). In addition to heavy metals, XCC preferentially removed salt from saline solutions. Salam et al. (2011b) reported that these materials could be used for desalination applications; in that study, $\mathrm{NaCl}$ was taken up at levels of $1.5 \mathrm{~g} / \mathrm{g}$ total salt uptake (bound/concentrated salt plus salt associated with water). It is also useful to determine if KI may be removed by XCC. This could be an important application when water is contaminated by radioactive iodine, which causes a number of health problems.
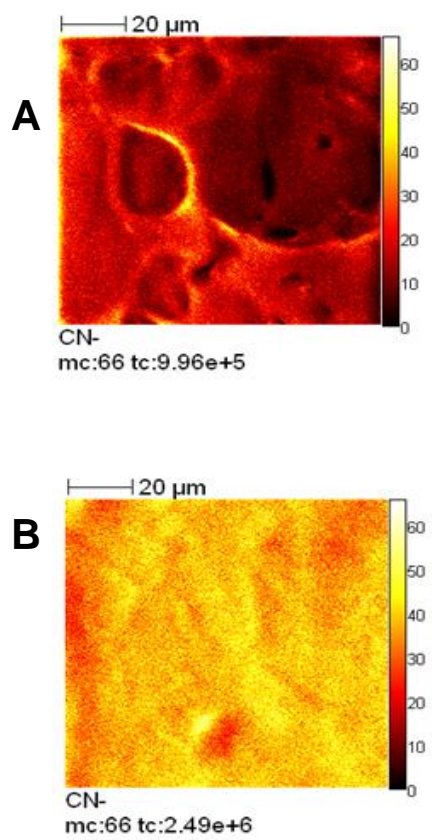

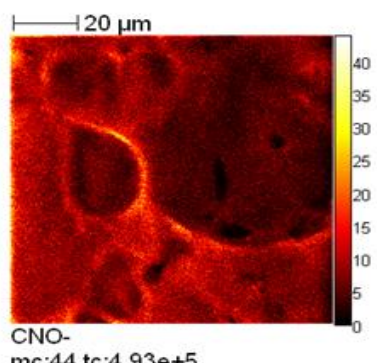

mc: 44 tc: $4.93 e+5$

Control Sample High Resolution Image
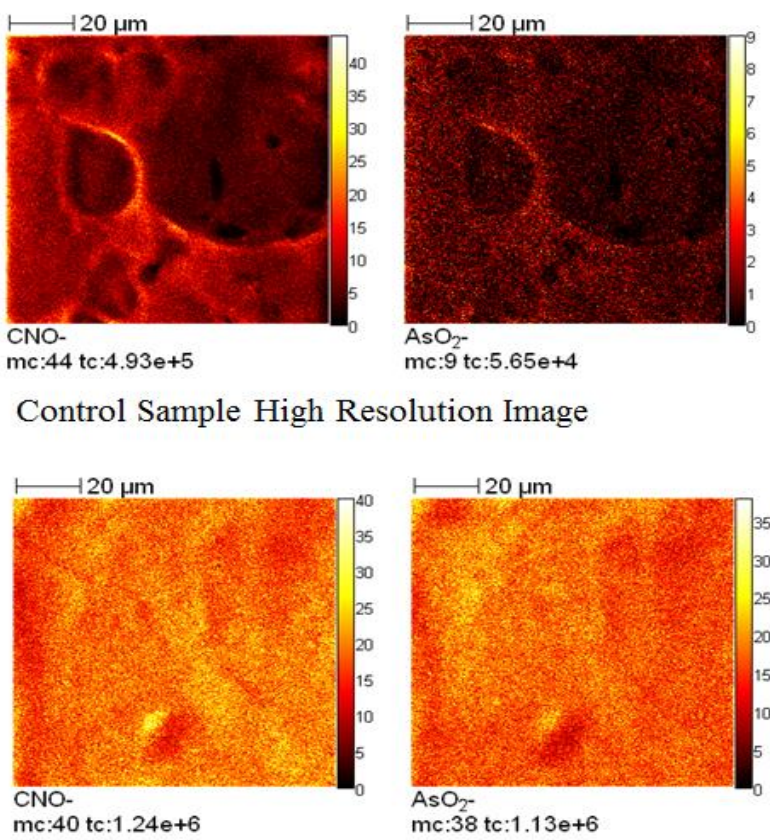

Arsenic Exposed Sample High Resolution Image
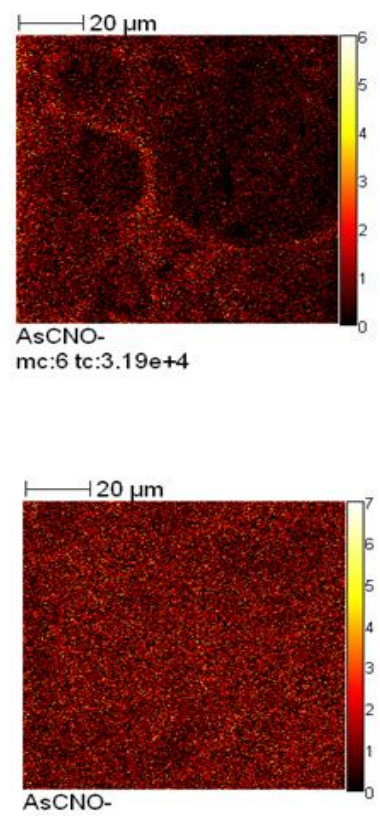

$\mathrm{mc}: 7 \mathrm{tc}: 6.59 \mathrm{e}+4$

Fig. 3. (A) TOF-SIMS high mass resolution image of control and (B) arsenic exposed SCC foam

The uptake of KI from a $3.5 \%$ KI by weight aqueous solution by XCC was determined to be $1.23 \mathrm{~g} / \mathrm{g}$ (gravimetric measurement after exposure and drying of XCC), $1.27 \mathrm{~g} / \mathrm{g}$ (conductivity measurement of solution before and after exposure to the XCC), and $1.47 \mathrm{~g} / \mathrm{g}$ (from a TGA determination after exposure of the XCC). The results indicate that about $1.3 \mathrm{~g} / \mathrm{g}$ of KI (bound/concentrated salt plus salt associated with water) can be adsorbed when the concentration of the $\mathrm{KI}$ is $3.5 \%$. 

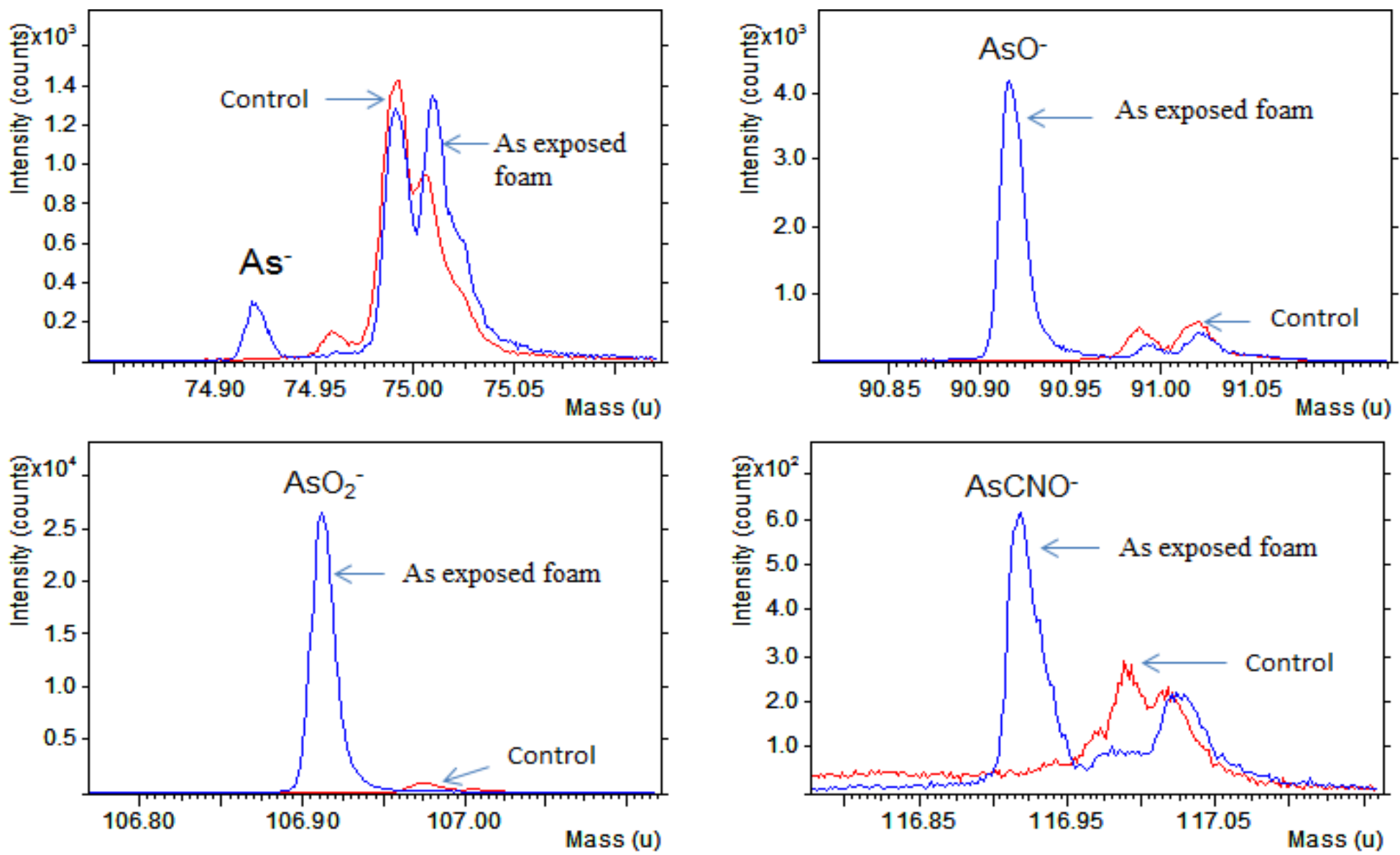

Fig. 4. The TOF-SIMS high mass resolution spectra of the control (-) and arsenic exposed (-) SCC foam 


\section{CONCLUSIONS}

1. Synthesized xylan citrate-chitosan (XCC) and starch citrate-chitosan (SCC) were shown to adsorb heavy metals and performed similarly to commercial adsorbents.

2. The carbohydrate-based materials adsorbed higher amounts of arsenic than the commercial materials.

3. Analysis via time-of-flight surface ionization mass spectrometry (TOF-SIMS) revealed that a complex between arsenic and the carbohydrate adsorbents was formed, presumable due to the oxygen and nitrogen lone pair electrons-metal complexes.

4. Absorption was modeled using a linearized Langmuir isotherm. Not all combinations of adsorbates and adsorbent materials fit this model well, indicating that they do follow the Langmuir isotherm absorption model. It was found that XCC performed well in adsorbing KI.

\section{ACKNOWLEDGMENTS}

This research project was funded by the Consortium for Plant Biotechnology and the United States Department of Energy (Grant No. DE-FG36-02GO12026) and the North Carolina Forestry Foundation.

\section{REFERENCES CITED}

Asere, T. G., Stevens, C. V., and Du Laing, G. (2019). "Use of (modified) natural adsorbents for arsenic remediation: A review," Science of the Total Environment 676, 706-720. DOI: 10.1016/j.scitotenv.2019.04.237

Belu, A. M., Graham, D. J., and Castner, D. G. (2003). "Time-of-flight secondary ion mass spectrometry: Techniques and applications for the characterization of biomaterial surfaces," Biomaterials 24(21), 3635-3653. DOI: 10.1016/S01429612(03)00159-5

Chatterjee, A., Das, D., Mandal, B. K., Chowdhury, T. R., Samanta, G., and Chakraborti, D. (1995). "Arsenic in ground water in six districts of West Bengal, India: The biggest arsenic calamity in the world. I: Arsenic species in drinking water and urine of the affected people," Analyst 120(3), 643-650. DOI: 10.1039/an9952000643

Dambies, L., Vincent, T., and Guibal, E. (2002). "Treatment of arsenic-containing solutions using chitosan derivatives: Uptake mechanism and sorption performances," Water Research 36(15), 3699-3710. DOI: 10.1016/S0043-1354(02)00108-2

Del Razo, L. M., Arellano, M. A., and Cebrián, M. E. (1990). "The oxidation states of arsenic in well-water from a chronic arsenicism area of northern Mexico," Environmental Pollution 64(2), 143-153. DOI: 10.1016/0269-7491(90)90111-O

Ebringerová, A., and Hromádková, Z. (1999). "Xylans of industrial and biomedical importance," Biotechnology and Genetic Engineering Review 16, 325-346. DOI: 10.1080/02648725.1999.10647982

Elson, C. M., Davies, D. H., and Hayes, E. R. (1980). "Removal of arsenic from contaminated drinking water by a chitosan/chitin mixture," Water Research 14(9), 
1307-1311. DOI: 10.1016/0043-1354(80)90190-6

Fan, Q., He, J., Xue, H., Lü, C., Sun, Y., Shen, L., Liang, Y., and Bai, S. (2008). "Heavy metal pollution in the Baotou section of the Yellow River, China," Chemical Speciation and Bioavailability 20(2), 65-76. DOI: 10.3184/095422908X322824

Frank, J. J., Poulakos, A. G., Tornero-Velez, R., and Xue, J. (2019). "Systematic review and meta-analyses of lead $(\mathrm{Pb})$ concentrations in environmental media (soil, dust, water, food, and air) reported in the United States from 1996 to 2016," Science of the Total Environment 694, article no. 133489. DOI: 10.1016/j.scitotenv.2019.07.295

Fujiwara, Y., Saito, N., Nonaka, H., Suzuki, A., Nakanaga, T., Fujimoto, T., Kurokawa, A., and Ichimura, S. (2011). "Time-of-flight secondary ion mass spectrometry (TOFSIMS) using the metal-cluster-complex primary ion of $\operatorname{Ir}_{4}(\mathrm{CO})_{7}{ }^{+}$," Surface and Interface Analysis 43(1-2), 245-248. DOI: 10.1002/sia.3435

Haider, S., and Park, S. -Y. (2009). "Preparation of the electrospun chitosan nanofibers and their applications to the adsorption of $\mathrm{Cu}$ (II) and $\mathrm{Pb}$ (II) ions from an aqueous solution," Journal of Membrane Science 328(1-2), 90-96. DOI: 10.1016/j.memsci.2008.11.046

Jenkins, P. J., and Donald, A. M. (1995). "The influence of amylose on starch granule structure," International Journal of Biological Macromolecules 17(6), 315-321. DOI: 10.1016/0141-8130(96)81838-1

Karadede, H., and Ünlü, E. (2000). "Concentrations of some heavy metals in water, sediment and fish species from the Atatürk Dam Lake (Euphrates), Turkey," Chemosphere 41(9), 1371-1376.

Khalil, M. I., and Abdel-Halim, M. G. (2001). "Preparation of anionic starch containing carboxyl groups and its utilization as chelating agent," Starch-Stärke 53(1), 35-41. DOI: 10.1002/1521-379X(200101)53:1<35::AID-STAR35>3.0.CO;2-V

Khalil, M. I., and Abdel-Halim, M. G. (2000). "Preparation of some starch-based neutral chelating agents," Carbohydrate Research 324(3), 189-199. DOI: 10.1016/S00086215(99)00290-6

Kim, B. S., and Lim, S. -T. (1999). "Removal of heavy metal ions from water by crosslinked carboxymethyl corn starch," Carbohydrate Polymers 39(3), 217-223. DOI: 10.1016/S0144-8617(99)00011-9

Kim, J. -S., Chah, S., and Yi, J. (2000). "Preparation of modified silica for heavy metal removal," Korean Journal of Chemical Engineering 17(1), 118-121. DOI: 10.1007/BF02789264

Kwok, K. C. M., Koong, L. F., Chen, G., and McKay, G. (2014). “Mechanism of arsenic removal using chitosan and nanochitosan," Journal of Colloid and Interface Science 416, 1-10. DOI: 10.1016/j.jcis.2013.10.031

Langmuir, I. (1918). "The adsorption of gases on plane surfaces of glass, mica and platinum," Journal of the American Chemical Society 40(9), 1361-1403. DOI: $10.1021 / \mathrm{ja} 02242 \mathrm{a} 004$

Lezzi, A., Cobianco, S., and Roggero, A. (1994). "Synthesis of thiol chelating resins and their adsorption properties toward heavy metal ions," Journal of Polymer Science Part A: Polymer Chemistry 32(10), 1877-1883. DOI: 10.1002/pola.1994.080321008

Lim, S. -H., and Hudson, S. M. (2004). "Synthesis and antimicrobial activity of a watersoluble chitosan derivative with a fiber-reactive group," Carbohydrate Research 339(2), 313-319. DOI: 10.1016/j.carres.2003.10.024

Liu, H., Du, Y., Yang, J., and Zhu, H. (2004). "Structural characterization and antimicrobial activity of chitosan/betaine derivative complex," Carbohydrate 
Polymers 55(3), 291-297. DOI: 10.1016/j.carbpol.2003.10.001

Matisoff, G., Khourey, C. J., Hall, J. F., Varnes, A. W., and Strain, W. H. (1982). "The nature and source of arsenic in northeastern Ohio ground water," Groundwater 20(4), 446-455. DOI: 10.1111/j.1745-6584.1982.tb02765.x

Matlock, M. M., Henke, K. R., Atwood, D. A. (2002). "Effectiveness of commercial reagents for heavy metal removal from water with new insights for future chelate designs," Journal of Hazardous Materials 92(2), 129-142. DOI: 10.1016/S03043894(01)00389-2

Mauro, D. J., Abbas, I. R., and Orthoefer, F. T. (2003). "Corn starch modification and uses," in: Corn: Chemistry and Technology J. W. Pamela, and A. J. Lawrence (ed.) American Association of Cereal Chemists, St. Paul, MN, pp. 605-634.

Mayer, J. E., and Goldman, R. H. (2016). "Arsenic and skin cancer in the USA: the current evidence regarding arsenic-contaminated drinking water," International Journal of Dermatology 55(11), e585-e591. DOI: 10.1111/ijd.13318

Morton, W., Starr, G., Pohl, D., Stoner, J., Wagner, S., and Weswig, P. (1976). "Skin cancer and water arsenic in Lane County, Oregon," Cancer 37(5), 2523-2532.

Nikolaidis, N. P., Dobbs, G. M., and Lackovic, J. A. (2003). "Arsenic removal by zerovalent iron: Field, laboratory and modeling studies," Water Research 37(6), 14171425. DOI: 10.1016/S0043-1354(02)00483-9

Prade, R. A. (1995). "Xylanases: From biology to biotechnology," Biotechnology and Genetic Engineering Reviews 13(1), 101-132. DOI: 10.1080/02648725.1996.10647925

PubChem. (n.d.). "Citric acid," < https://pubchem.ncbi.nlm.nih.gov/compound/Citricacid> (Mar. 28, 2021).

Salam, A., Pawlak, J. J., Venditti, R. A., and El-Tahlawy, K. (2010). "Synthesis and characterization of starch citrate-chitosan foam with superior water and saline absorbance properties," Biomacromolecules 11(6), 1453-1459. DOI: $10.1021 / \mathrm{bm} 1000235$

Salam, A., Pawlak, J. J., Venditti, R. A., and El-Tahlawy, K. (2011a). "Incorporation of carboxyl groups into xylan for improved absorbency," Cellulose 18(4), 1033-1041. DOI: $10.1007 / \mathrm{s} 10570-011-9542-\mathrm{y}$

Salam, A., Venditti, R. A., Pawlak, J. J., and El-Tahlawy, K. (2011b). "Crosslinked hemicellulose citrate-chitosan aerogel foams," Carbohydrate Polymers 84(4), 12211229. DOI: 10.1016/j.carbpol.2011.01.008

Shchipunov, Y., Sarin, S., Kim, I., and Ha, C. S. (2010). "Hydrogels formed through regulated self-organization of gradually charging chitosan in solution of xanthan," Green Chemistry 12(7), 1187-1195. DOI: 10.1039/b925138c

Sillanpää, M., and Oikari, A. (1996). "Assessing the impact of complexation by EDTA and DTPA on heavy metal toxicity using microtox bioassay," Chemosphere 32(8), 1485-1497. DOI: 10.1016/0045-6535(96)00057-4

Sola, I., Ausio, X., Simo, R., Grimalt, J. O., and Ginebreda, A. (1997). "Quantitation of volatile sulphur compounds in polluted waters," Journal of Chromatography A 778(1-2), 329-335. DOI: 10.1016/S0021-9673(97)00415-9

Welch, A. H., Lico, M. S., and Hughes, J. L. (1988). "Arsenic in ground water of the western United States," Groundwater 26(3), 333-347. DOI: 10.1111/j.17456584.1988.tb00397.x। 
Zobrist, J., Sima, M., Dogaru, D., Senila, M., Yang, H., Popescu, C., Roman, C., Bela, A., Frei, L., Dold, B., and Balteanu, D. (2009). "Environmental and socioeconomic assessment of impacts by mining activities-a case study in the Certej River catchment, Western Carpathians, Romania," Environmental Science and Pollution Research International 16(Suppl 1), 14-26. DOI: 10.1007/s11356-008-0068-2

Article submitted: January 31, 2019; Peer review completed: May 14, 2019; Revised version received and accepted: May 12, 2021; Published: June 23, 2021.

DOI: 10.15376/biores.16.3.5628-5645 